\title{
Arqueologia rural galo-romana e ideologia moderna
}

\author{
Uiran Gebara da Silva*
}

SILVA, U.G. Arqueologia rural galo-romana e ideologia moderna. R. Museu Arq. Etn., 28: 42-57, 2017.

Resumo: $\bigcirc$ objetivo deste trabalho é avaliar recentes representações historiográficas das regiões rurais da Gália tardo-romana. Com o aumento e a expansão do escopo da arqueologia rural nesse período, em substituição a uma visão de um Império em decadência, passou-se progressivamente a visões que propõem crescimento econômico e comercial nas regiões rurais do Império. Observando o caso específico do norte da Gália tardo-romana, a avaliação dessas representações busca refletir a respeito dos métodos de investigação nos quais se baseiam a arqueologia rural, principalmente o papel da survey archaeology na produção de sítios sub-villa e das interpretações dos achados nesses sítios em termos da criação de mercados locais. Uma vez que essa perspectiva de crescimento econômico se dá no contexto também da reelaboração da perspectiva modernista no estudo da Economia Antiga por meio da aplicação da New Institutional Economics como enquadramento teórico, critica-se os parâmetros modernizantes de interpretação do quadro representado pela documentação material e problematiza-se o uso da ideia de desenvolvimento econômico inspirado em referências de desenvolvimento capitalista. Em contrapartida, busca-se propor formas de lidar com esse quadro documental de forma a elaborar modelos de processos sociais e econômicos mais complexos e dinâmicos do que a historiografia do século XX reconhecia para as regiões rurais da Gália tardo-romana.

Palavras-chave: Gália romana; Campesinato; Arqueologia rural; Mercados locais; Regionalização.

$\mathrm{O}$ título deste artigo é uma pequena provocação que se endereça tanto a meus interlocutores no campo de estudos do qual participo quanto ao meu próprio trabalho. O estudo que apresento aqui busca, em primeiro lugar, avaliar as representações historiográficas que se desenvolveram nas últimas décadas a respeito das regiões rurais do Império Romano, em particular na Gália tardo-antiga. Busca também

${ }^{*}$ ) Pós-doutorando em História Antiga no Departamento de História na Universidade de São Paulo com auxílio Fapesp. <uirangs@gmail.com> servir de alerta não apenas para os pressupostos teóricos dessa historiografia, mas também para as conformações sociais, políticas e ideológicas a partir das quais meu próprio trabalho como historiador é produzido. Retornarei a esta questão ao final do texto, depois de ter apresentado as representações historiográficas a que me refiro.

\section{Da crise à transformação}

Até os anos 1960 e 1970, imperava na historiografia sobre o Império Romano 
tardio um paradigma que postulava que o Império tinha acabado sob um processo de decadência e crises generalizadas. Dentre os grandes debates historiográficos do século XX estava exatamente aquele que girava em torno dos fatores que levaram ao fim do Império Romano, com teorias variadas e contraditórias as quais enfatizavam ora o plano político, ora o econômico, ora o cultural.

No plano econômico, no qual me concentrarei neste estudo, as explicações mais aceitas para crise social eram as que propunham a hipótese de uma crise do escravismo (Weber 1983) e, dentre os estudiosos marxistas, do modo de produção escravista (Anderson 2000; Staerman 1980). Essa perspectiva defendia que o elemento fundamental causador da decadência da civilização antiga teria sido a interrupção do fornecimento da mão de obra escrava no século II. Em complementação a este processo, sob a alcunha de colonato, teria acontecido um reforço da dominação aristocrática sobre os trabalhadores rurais, entre os séculos III e VI. Neste sentido, essa visão considerava que teria piorado drasticamente a situação social das classes subalternas das regiões rurais do Império tardio.

O paradigma de crise e decadência do Império Romano permaneceu sendo bem aceito até os anos 1980. No entanto a sua desconstrução já vinha sendo preparada ao longo das duas décadas anteriores, conforme apareciam inúmeras pesquisas pontuais que problematizaram, questionaram e o desconstruíram. Os novos estudos sobre o Império tardio se desenvolveram tanto por meio do refinamento da compreensão das estruturas literárias das fontes textuais quanto da profusão de estudos arqueológicos.

Sob o impacto desses novos estudos, entre os anos 1960 e 1970 houve uma profunda transformação das representações historiográficas do Império Romano entre os séculos III e VI, o que resultou também na criação de uma nova periodização e de um novo campo de investigações: a Antiguidade Tardia. A ideia de que houve uma crise do escravismo começou a ser desmontada por Moses Finley (1999) e para muitos historiadores o século III deixou de ser considerado um período de crise social ou econômica, seguindo as sugestões do trabalho pioneiro de Peter Brown, The world of late antiquity (1971).

No mesmo passo, a historiografia social e econômica sobre os séculos III a $\mathrm{V}$ também mudou bastante. Os estudiosos passaram a ver o crescimento e enriquecimento nos séculos II a.C. a II d.C. como excepcionais para padrões típicos de sociedades pré-industriais, principalmente na Itália, e a entender o século III mais como uma etapa de reajuste. Ao olhar o Império como um todo, seria possível ver uma espécie de equilíbrio sendo estabelecido entre as províncias e o centro a partir de então (Leveau 2007: 651-670; Saller 2005; Schiavone 2005). Um reajuste social e político também pode ser visto, em termos muito semelhantes, na reconfiguração das relações entre as elites locais e regionais e a corte imperial, marcada pela ascensão de novos centros imperiais e novos canais de poder local a eles associados (Matthews 1990).

Assim, até o começo do século XXI, o paradigma interpretativo não era mais o da crise, da decadência ou da queda do Império Romano. No lugar desses conceitos, houve o uso cada vez mais indiscriminado das noções de continuidade e mudança, que proporiam para o período da Antiguidade Tardia uma caracterização pautada por transformações lentas e sem rupturas, enfatizando cada vez mais as continuidades e as trocas culturais (Cameron 1993; Carrié \& Rousselle 1999). Mais recentemente, alguns pesquisadores trouxeram novamente a perspectiva de crises (política, social e/ou econômica) para explicar a desagregação do Estado romano nos séculos III e V. O século III é analisado considerando crises bem mais específicas, como a crise militar ou a política (De Blois 2002; Heather 2006; Liebeschuetz 2007). A crise do século V, contudo, é apresentada como sendo mais súbita e também resultante de problemas militares e da incapacidade dos romanos em lidar com os bárbaros, que, neste caso, levará ao fim do domínio romano sobre as regiões ocidentais do Império (Heather 2006; Ward-Perkins 2005). 


\section{As regiões rurais do Império}

No que diz respeito à compreensão das regiões rurais do Império Romano tardio, tais críticas resultaram, em primeiro lugar, em mudanças nos próprios modelos conceituais adotados para explicar as relações sociais nas zonas rurais do Império. Além disso, por meio do avanço da arqueologia nesse campo de estudo, revisou-se uma série de noções anteriormente consensuais, entre elas: a excessiva centralidade dada às villae, a ideia de colonato tardo-romano e a homogeneidade do escravismo romano. Em meio ao contexto historiográfico esboçado na seção anterior, passou-se progressivamente a visões que propõem crescimento econômico e comercial nas regiões rurais do Império.

As evidencias materiais e textuais serviram de base para formulação de modelos que descrevem processos de intensificação da produção e de desenvolvimento de redes de comércio inter-regional, regional e até mesmo local (Horden \& Purcell 2000). O aumento e a expansão do escopo da arqueologia rural que cobre esse período possibilitaram a constatação da manutenção e, em certos lugares, do crescimento do número de sítios rurais, de sinais de difusão de objetos artesanais produzidos em larga escala e da monetarização das regiões rurais, inclusive para as classes sociais mais baixas, entre as quais tais objetos, produtos e moedas estavam ausentes (ou ainda são invisíveis para os pesquisadores) antes do século III. Muito embora os núcleos dinâmicos desses modelos sejam a África (Fentress 1993; Ghedini 1993; Mattingly \& Hitchner 1995), o Egito (Bagnall 2005) e o Levante (Ward-Perkins 2005: 124 126), propostas semelhantes estão sendo desenvolvidas para outras províncias, com graus menores de intensidade, como a Gália (Février 1993; Ouzoulias \& Van Ossel 2000; Tuffi 1993) e a Hispânia (Arce 1993).

A historiografia, também sem muito consenso, tem interpretado as causas e os impactos sociais desses processos de intensificação econômica (Bowden, Lavan \& Machado 2004; Grey 2011). Em primeiro lugar, aponta a reorganização do sistema tributário estatal como elemento importante para compreensão das transformações sociais. Nesse sentido, ainda tem papel importante o desenvolvimento de estruturas legais e coercitivas que visam ao maior controle da mão de obra rural a partir do Estado, muito embora seu impacto a longo prazo não seja mais tão duradouro e a capacidade da aristocracia de aproveitar-se plenamente disso seja contestada por alguns autores (Carrié 1982, 1983; Grey 2011). A esse controle jurídico da mão de obra é acrescentada a ideia de que haja um processo de concentração de propriedade da terra, a qual não se cristaliza em latifúndios, e sim no controle fragmentado de inúmeras parcelas em escala inter-regional, mas leituras diferenciadas e até contraditórias foram apresentadas. Tanto Chris Wickham (2005) quanto Jairus Banaji (2007) interpretam os processos de intensificação como resultado do aumento das taxas de exploração do trabalho camponês, o qual se dava por meio do maior controle da extração das rendas rurais - que se dividem entre o pagamento ao proprietário e o pagamento dos impostos, mais bem controlado a partir do século IV - e da concentração da propriedade ${ }^{1}$.

\section{Mercados locais e melhoria de padrões de vida na Gália setentrional}

Tendo essa mudança de paradigma como pano de fundo, tem sido comum interpretar os achados arqueológicos e os processos de intensificação em termos de expansão de mercados locais, regionais e inter-regionais. Essa perspectiva, em geral, associa o impacto do crescimento dos mercados locais rurais à ideia de uma melhoria dos padrões de vida no campo entre os séculos III e V. Essa melhoria é apresentada com graus e entusiasmo variados para as diferentes regiões do Império (Dossey 2010;

1 Carlos Mac Gaw (2012) chama atenção para o enquadramento modernista e as implicações da visão de Banaji sobre as relações de trabalho na Antiguidade. 
Leveu 2007; Ouzoulias \& Van Ossel 1997; Ouzoulias \& Van Ossel 2000; Van Ossel 2006; Ward-Perkins 2000, 2005).

Analiso, nesta seção, alguns dos estudos de natureza mais empírica a partir dos quais essa interpretação tem sido depreendida para a Gália tardo-romana setentrional. Para isso, lido com alguns dos estudos arqueológicos que apresentam as regiões rurais da Gália tardoromana com maior dinamismo econômico e social que a historiografia anterior, tendo em mente a mudança metodológica que resultou neles.

A arqueologia rural romana, durante muito tempo, concentrou-se na investigação das grandes mansões rurais dos aristocratas romanos: as villae. O estudo dessas villae, por sua vez, era realizado fundamentalmente por meio da escavação da grande habitação, facilmente identificada e delimitada. Boa parte do esforço dos pesquisadores se direcionava para a compreensão das divisões internas da casa, da delimitação do território ao redor e dos usos do espaço - por exemplo, as regiões destinadas ao aristocrata e aquelas reservadas aos escravos. Dessa forma, a compreensão das relações sociais no campo do ponto de vista da arqueologia era guiada pelo estudo arquitetônico dessas mansões (Becker \& Terrenato 2012; Dyson 2003). Isso acontecia tanto na Itália, região central do Império, mas também nas províncias como a Gália (Ouzoulias \& Van Ossel 2000).

A partir da metade do século XX, os novos métodos começaram a ampliar as opções dos arqueólogos para além do uso exclusivo da escavação. A arqueologia aérea, observação a partir de uma aeronave da paisagem rural, teve grande impacto nos estudos sobre centuriação e na descoberta de novos sítios rurais. Além disso, o uso cada vez mais frequente da survey archaeology, isto é, a investigação extensiva de uma região em busca de vestígios na superfície, ampliou a compreensão do quadro geral da ocupação rural do norte da Gália no período. $\mathrm{O}$ resultado dessa mudança metodológica foi tornar visíveis muitos assentamentos de tamanho inferior aos das villae. Isso significou, por sua vez, um aumento significativo no material de estudo disponível para os arqueólogos do período romano e tardo-romano ${ }^{2}$ cujos impactos mencionei há pouco.

\section{Terra e habitação rural}

Os estudos arqueológicos mais antigos sobre a Gália, que se concentravam nas villae, articulavam-se perfeitamente com os modelos de crise e decadência. Neles, identificava-se um processo de diminuição do número de mansões no norte da Gália a partir do século III e, em muitos casos, constatava-se o uso cada vez mais comum de técnicas de construção com madeira no lugar de pedras e tijolos nas habitações que se mantinham.

O paradigma de crise e decadência era tão consolidado que, em um primeiro momento, tentou-se encaixar nele a descoberta dos assentamentos rurais menores e a constatação então verificada, mas hoje já revista, de que essa ocupação rural tendia à concentração em torno de certos polos (Ouzoulias \& Van Ossel 2000). Esses assentamentos representariam o controle rígido que os grandes proprietários exerciam sobre o trabalho rural por meio do crescimento do número de trabalhadores em regime de arrendamento e da diminuição do número de camponeses pequenos proprietários. Por causa da descoberta, perto do Reno e do Mosela, de muitos vici que se transformaram em civitas muradas, sugeriuse então a existência de uma sociedade rural polarizada entre comunidades rurais empobrecidas e potentados poderosíssimos morando em núcleos urbanos fortalecidos (Wightman 1978).

O avanço da investigação sobre os assentamentos menores demonstrou que a dispersão ainda se mantinha no século IV e V e que seu número variava muito pouco entre os séculos III e IV, apresentando uma pequena mudança de localização em alguns casos (Louis 2004; Ouzoulias \& Van Ossel 2000).

2 Uma síntese dessas mudanças está em Dyson (2003) e em Chavarría \& Lewit (2004). 
As Figuras 1 e 2 apresentam a manutenção do padrão de dispersão dos assentamentos rurais na região de Aldenhoven na Renânia ao longo do século IV. A constatação da pequena variação (para baixo) e da manutenção do padrão de dispersão por um lado permite questionar o cenário de decadência desenhado

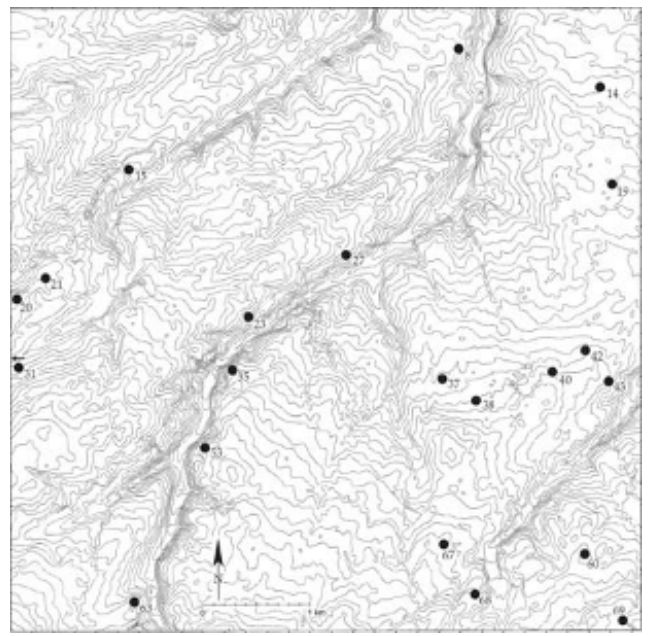

Fig. 1. Distribuição de assentamentos em Aldenhoven na Renânia. Primeiro e segundo terços do século IV. Fonte: Lenz (1999 apud Van Ossel 2006).

Um dos grandes problemas dos modelos anteriores era que eles buscavam extrair dos assentamentos e de seus territórios padrões de propriedade da terra. Tendo por base as teorias sobre o colonato, esses modelos igualavam o processo de nucleação dos assentamentos ao processo de concentração da propriedade da terra por potentados locais. Nesse sentido, os estudos mais recentes têm se esforçado para desarticular essa equivalência. Em primeiro lugar, a constatação de que a dispersão dos assentamentos se mantinha retirou uma das bases em que ela se apoiava, e, em segundo lugar, os investigadores têm insistido na impossibilidade de equacionar regimes de propriedade com padrões de assentamento. Apenas tem se arriscado a identificar a extensão territorial de propriedades rurais em casos bem particulares, como certas localidades nos arredores de Trier e Bitburg, regiões de intensa pelo modelo anterior e acentuar algumas continuidades de organização social rural nessa região. Por outro, deve-se notar que isso significa que há, efetivamente, algum declínio no número dos assentamentos (aproximadamente 75\%), embora não tão dramático quanto se pensava.

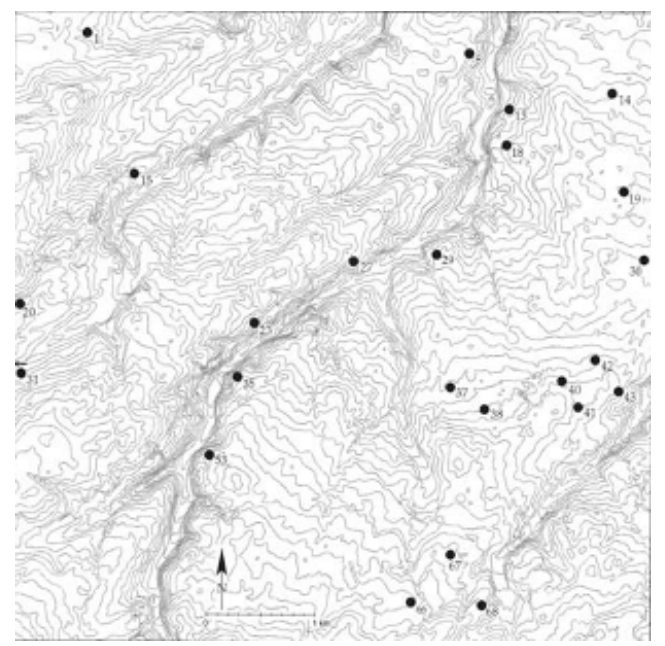

Fig. 2. Distribuição de assentamentos em Aldenhoven na Renânia. Final do século IV.

Fonte: Lenz (1999 apud Van Ossel 2006).

atividade militar, em que há muros demarcando a extensão da propriedade (Ouzoulias \&

Van Ossel 2000: 153). Assim, a hipótese da concentração de propriedade da terra pode não estar errada, porém ela não se deu na forma do latifúndio ${ }^{3}$ e não deixou registros materiais nos assentamentos.

Articula-se ao que desenvolvi até aqui outra mudança importante na interpretação dos assentamentos com habitações menores. Habitações feitas de madeira ou pequenos edifícios de armazenamento - principalmente as chamadas sunken house ou Grubenhaus -, que apareciam na Gália setentrional no século III, eram anteriormente interpretadas como sinais de migrações dos povos bárbaros, já que surgem

3 O modelo de concentração de propriedade baseado no domínio disperso e que é aceito como referência atualmente foi sugerido por Domenico Vera (1986). 
também além da fronteira militar. Essa leitura tem sido substituída pela proposta de que elas seriam habitações das camadas rurais mais pobres, tratando-se mais de uma convergência técnica do que sinais de migração, dado seu grande número e sua presença em assentamentos que não apresentam nenhum vestígio material de presença bárbara (Ouzoulias \& Van Ossel 2000: 149).

A Figura 3 apresenta algumas plantas de habitações encontradas também na região da Renânia e que apresentam sinais de ocupação no séc. IV. A habitação A
(Rheinbach-Flerzheim, na planície renana) possa ser claramente qualificada como a tradicional villa. No entanto, a habitação B, chamada fazenda de Hambach 32 (platô de Düren), é bem menor e apresenta elementos de construção bem mais simples do que o se esperaria de uma mansão rural. $\mathrm{O}$ mesmo pode ser dito do pequeno edifício $\mathrm{C}$ em Bollendorf, que apresenta a construção de um recinto de banho no final do século III, e a D em Trier, que junto a paredes de pedra apresenta paredes feitas de cob (terra, argila, palha e areia).

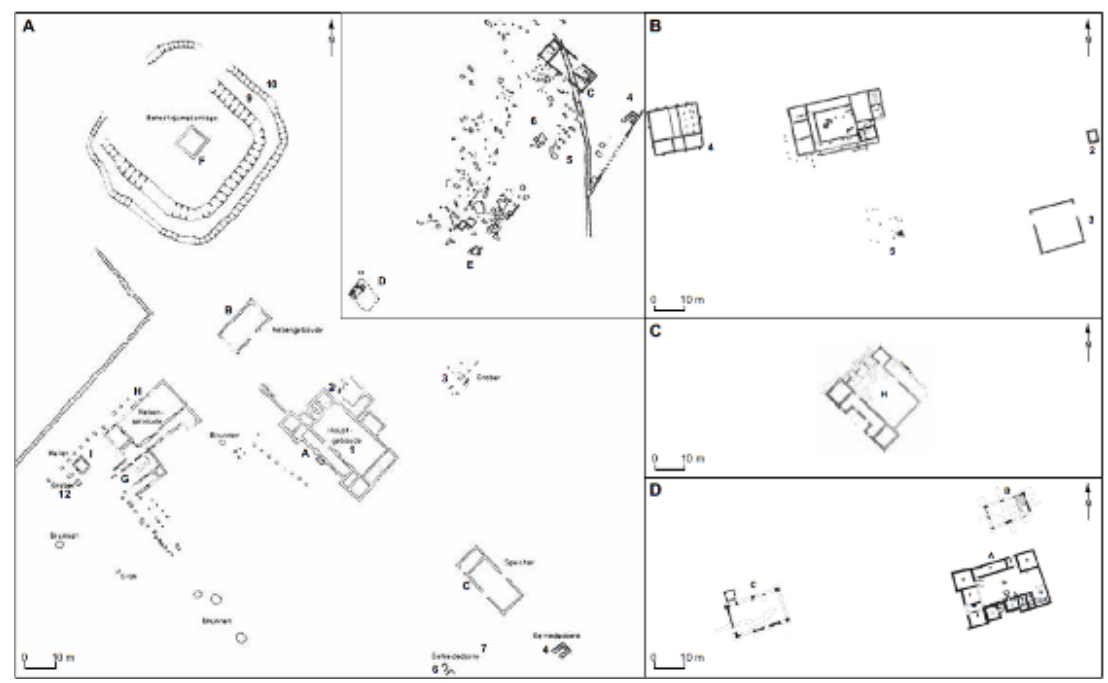

Fig. 3. Diversidade de assentamentos no século IV.

Fonte: Van Ossel (2006).

Esses são alguns dos exemplos da grande diversidade das habitações que se revelaram nas regiões rurais da Gália setentrional. Essa variedade, por indicar a existência de uma grande diversidade de níveis sociais entre os habitantes rurais galo-romanos, coloca dificuldades para a interpretação da Gália tardoromana como uma sociedade baseada na aguda polarização social. O caso do compartimento para banho construído no edifício $\mathrm{C}$ pode, por exemplo, representar ascensão social do seu proprietário e seria representativo dessa diversidade, tanto em termos de status e prestígio quanto em termos de variedade de relações com o trabalho e com a terra.
Complementarmente, sugeriu-se que o edifício D representaria uma mudança nas técnicas de construção, com o objetivo de tornar o edifício mais apropriado para usos ligados à função produtiva (Van Ossel 2006).

\section{Objetos seriados: cerâmica}

Embora seja um elemento importante, apenas a variação das habitações não constitui base empírica suficiente para essa perspectiva que atribuiu ao campo galo-romano maior diversidade social. Nos sítios e assentamentos entre os séculos III e V, é comum encontrar 
objetos variados cujos materiais e técnicas de construção, assim como os usos e valores simbólicos, também servem de base para ver ali uma maior diversidade social. Dadas as limitações de espaço, pretendo me concentrar em apenas duas categorias de objetos encontrados nos assentamentos cujo volume e recorrência permitem avaliar melhor a hipótese de maior diversidade social: a cerâmica e as moedas.

Essas duas categorias de objetos são sempre comemoradas quando encontradas porque geralmente oferecem, do ponto de vista metodológico, possibilidades maiores de estabelecimento de datações relativas, ou mesmo absolutas, no caso das moedas. Para isso, contribuem vários fatores derivados da sua condição de vestígio material. Sua profusão e distribuição em meio aos locais investigados, assim como sua facilidade de comparação com objetos semelhantes, estabelecem a possibilidade de generalizações que outros tipos de objetos, mais raros, não oferecem. Adicionalmente, tanto as moedas quanto a cerâmica romanas apresentam uma condição seriada facilmente identificável por meio do estudo da sua produção: a cerâmica, por causa do seu material, da evolução das técnicas e dos estilos das decorações nelas encontradas; e as moedas, por causa da possibilidade de as datar precisamente, dados os símbolos e as informações presentes nas cunhagens. Isso torna ambas categorias de objetos importantíssimas para a construção de cronologias que permitem a datação dos lugares ou níveis onde foram encontradas, possibilitando, consequentemente, a datação de outros objetos.

A cerâmica encontrada na região é, também, bem diversificada e apresento aqui dois tipos de material: a sigillata de Argonne, e o que é costumeiramente chamado de Roman Coarse Ware ("louça romana grosseira") de Mayen. Ambas servem de base para a hipótese de maior diversidade social, assim como para a ideia de que houve nessas áreas a formação de mercados locais.

A sigillata de Argonne é considerada uma cerâmica de produção seriada, com coloração vermelha do tipo terra sigillata, originária da região da floresta de Argonne no norte da França, e geralmente se apresenta no formato de tigela com uma decoração característica composta por pequenos padrões em sua base e no disco de sustentação. Nas Figuras 4, 5 e 6 temos apresentados mapas de difusão da cerâmica sigillata de Argonne. Aqui estou menos interessado na evolução temporal da distribuição que na sua distribuição sincrônica na fase 2 (410 a 450$)$ e na fase $3(450-470)$. A variação do número de assentamentos onde elas são encontradas entre essas duas fases é pequena, principalmente se considerarmos a intensa atividade militar no norte da Gália no século V. É importante notar o raio de alcance da distribuição dessa cerâmica na fase 2 , já que na fase 1 , século III até início do IV, ela é encontrada inclusive na Britânia.

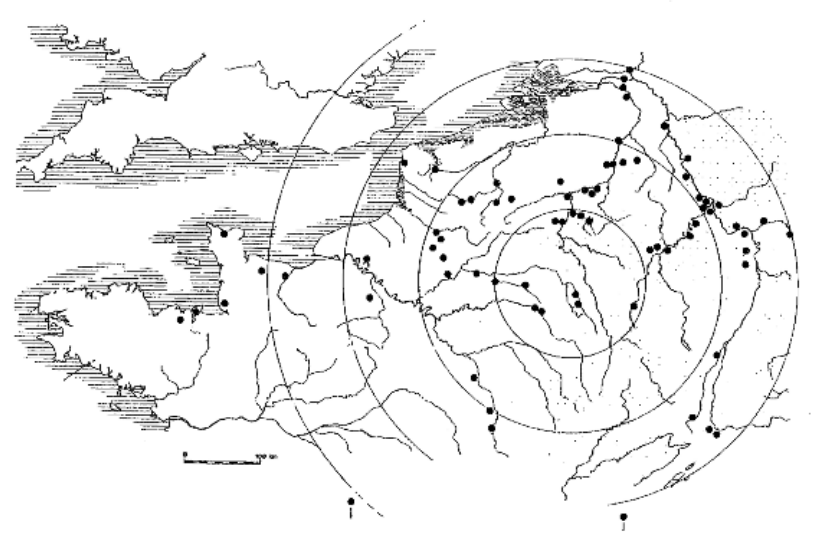

Fig. 4. Difusão da sigillata de Argonne ao longo da fase 2 (c.410-c.450).

Fonte: Bayard (1998). 


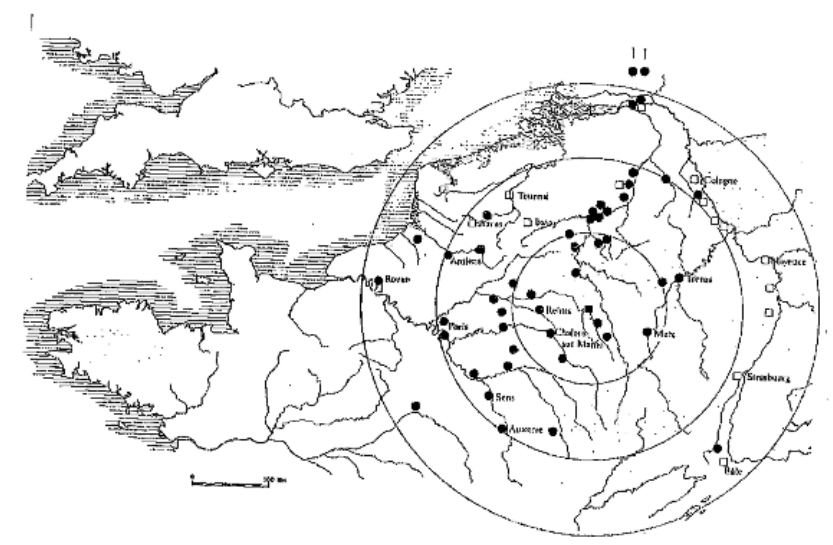

Fig. 5. Difusão da sigillata de Argonne ao longo da fase 3 (450-470).

Fonte: Bayard (1998).

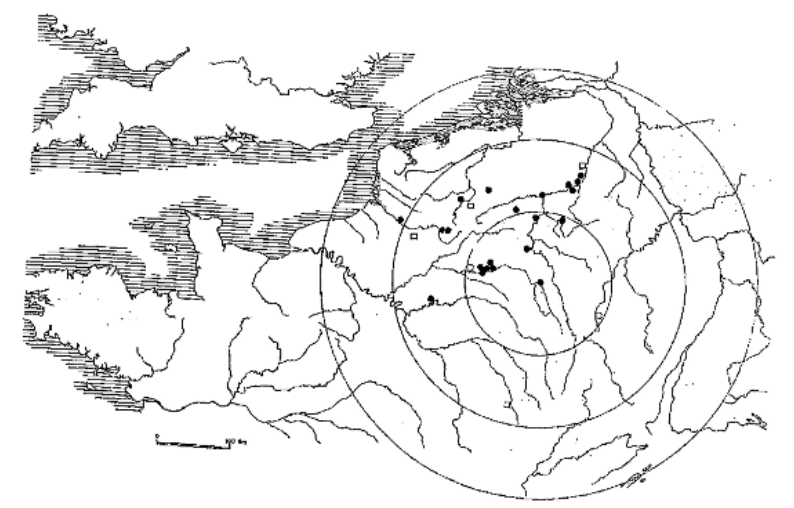

Fig. 6. Difusão da sigillata de Argonne ao longo da fase 4 (490?-530/40).

Fonte: Bayard (1998).

A proximidade de rios é um fator importante para o transporte, e essa ampla difusão pode ser associada a duas estruturas de distribuição: político-militar ou comercial (Bayard 1998). Exatamente por causa da presença comum desse tipo de cerâmica em assentamentos militares, alguns estudiosos interpretam que sua distribuição é orientada principalmente pelas necessidades da logística governamental romanas. Contudo essa cerâmica não se encontra exclusivamente nesse tipo de assentamento, sendo também comumente descoberta em villae e em habitações rurais galo-romanas de porte médio e pequeno. Isso significa que pode haver uma articulação entre uma coisa e outra, de forma que a interação com o contexto militar pode ter estimulado a produção dessa cerâmica e sua distribuição, via comércio local e regional, para usos cotidianos (Van Ossel 2006: 560).

A "louça romana grosseira" de Mayen, é uma cerâmica de formato e técnicas rústicas de produção, mas ainda assim seriada cujas oficinas são encontradas na região de Eiffel na França. Essa louça de Mayen é distinguível das outras por causa da composição particular de sua argila, que é facilmente identificável. Ela se encontra em muitos formatos diferentes, como pratos, tigelas, vasos e jarros, com coloração acinzentada ou amarelada. Como se pode ver na Figura 7, ela apresenta um padrão de difusão diferenciado em relação à sigillata de Argonne. Embora também 
acompanhe o Reno, ela tem menor raio de alcance para as regiões a oeste do seu centro de produção, não tendo tanta presença nos assentamentos na Bélgica e na região a norte do Loire, além disso é uma das poucas "louças grosseiras" gálicas que são encontradas na Britânia. A quantidade na qual é encontrada, contudo, é grande.

A Roman Coarse Ware de Mayen, não surpreendentemente, com suas oficinas em região de fronteira e tendo sua difusão acompanhando o rio, também é associada a contextos militares (Redknap 1988). Porém, não aparece apenas em habitações de porte médio ou maior, mas também nos assentamentos menores, inclusive os que apresentam sinais de construção em madeira. Assim, o mesmo tipo de articulação entre as necessidades militares e circulação comercial do excesso da produção é utilizada para associar os achados dessa cerâmica à hipótese de mercados locais. Nesse caso, contudo, seriam mercados e circuitos comerciais de menor porte, com consumidores de poder aquisitivo mais baixo, camponeses e habitantes das regiões rurais integrados a uma rede comercial menor, mas em interação com os circuitos maiores associados à sigillata de Argonne.

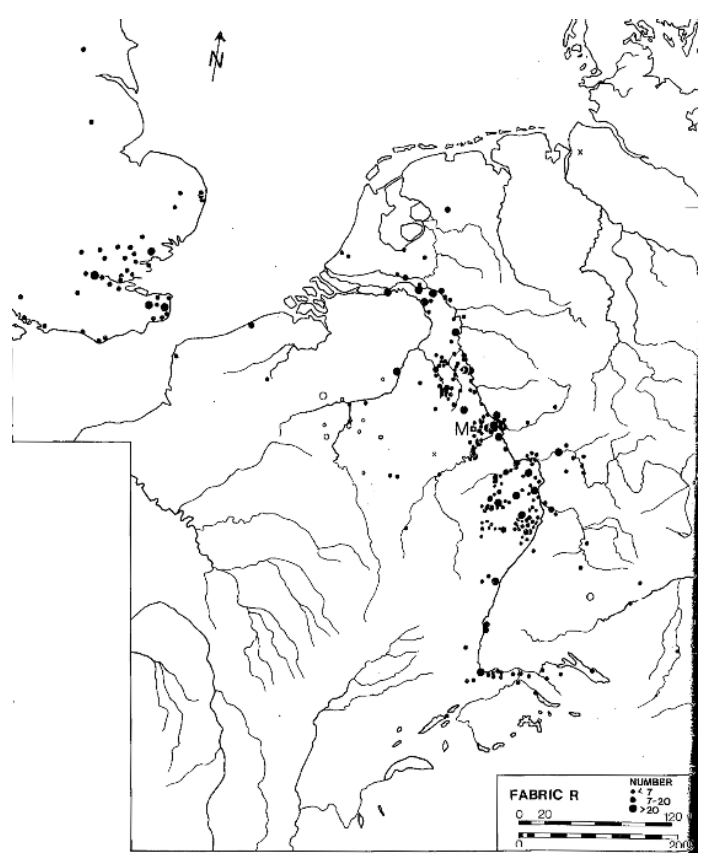

Fig. 7. Distribuição da cerâmica de Mayen tardo-romana.

Fonte: Redknap (1988).

\section{Objetos seriados: moedas}

O outro pilar da hipótese dos mercados locais é a ideia de uma monetarização do norte da Gália tardo-romana. A base empírica da monetarização é a descoberta de grandes quantidades de moedas nos assentamentos rurais. Esses achados de moedas galo-romanas do final do século III e do IV (muito poucas são achadas no V) têm características particulares em relação aos séculos anteriores. Há neles uma queda significativa da quantidade de moedas de prata, um aumento também significativo do número de exemplares de moedas de ouro e a quantidade de moedas de bronze é bem maior do que qualquer um dos outros dois materiais. Adicionalmente, é importante notar que o maior número de moedas de bronze também se dá comparativamente com relação a depósitos dos séculos I e II e, a partir disso, tem sido defendido 
que conforme o ouro se tornava a moeda de referência para grandes valores no Império tardio, o uso do bronze se difundiu entre as camadas sociais mais baixas, começando a fazer parte das transações comerciais cotidianas nas regiões setentrionais da Gália (Ouzoulias \& Van Ossel 2000: 155; Van Ossel 2006: 558-559).

A Figura 8 e a Tabela 1 foram retiradas de uma publicação dos estudos de Bruno Foucray (1997) sobre os depósitos de moedas encontrados a partir de prospecções realizadas na região da Ilede-France. Esta região não era muito importante do ponto de vista econômico e político entre os séculos III e V, mas ainda assim há número significativo de depósitos de moedas. A Figura 8 é uma representação espacial da difusão somente de moedas de ouro e de prata e seus respectivos depósitos e, como se pode ver, os depósitos se distribuem de forma equilibrada ao longo desse período e do espaço analisado.

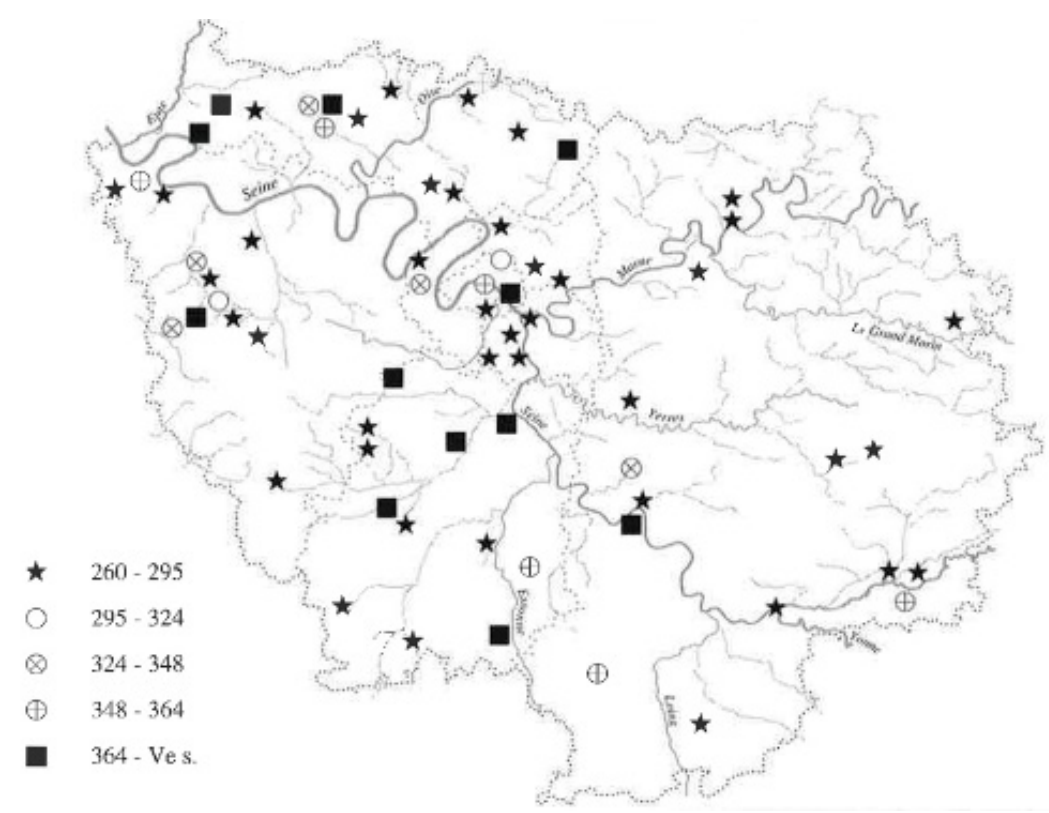

Fig. 8. Mapa dos depósitos monetários e moedas de ouro na Ile-de-France.

Fonte: Foucray (1997).

A Tabela 1 apresenta a composição dos depósitos e a relação entre a datação e a localização deles. É importante frisar que a grande maioria dos exemplares encontrados é de moedas de bronze, o que por sinal ajudou Foucray a estabelecer a cronologia, uma vez que as moedas de bronze passaram recorrentemente por ponderações no seu valor ao longo do séc. IV. Há mais uma característica importante que pode ser visualizada nessa tabela: a grande quantidade de imitações encontradas, que se concentram nas fases 3 (330-348) e 4 (348-364) e, particularmente no caso de moedas datadas de 354-358, no depósito de Vert-Saint-Denis.
Repare também, nesse caso, a grande quantidade de moedas não datáveis, mas que provavelmente também seriam imitações do século IV.

A hipótese proposta por Foucray para explicar essas imitações de moedas de bronze é que deveria haver no séc. IV um uso corrente delas para o comércio que justificasse a produção e circulação dessas imitações. Adicionalmente, as imitações também poderiam representar a continuidade do uso dessas moedas de bronze mesmo depois da interrupção de sua cunhagem no final do séc. IV (Foucray 1997: 45). 


\begin{tabular}{clcccccc}
\hline Fases & \multicolumn{1}{c}{ Períodos } & Videlles & Brie Comte-Robert & Vert-Saint-Denis & Beaumont & Grigny & Linas \\
\hline 1 & Antes de 318 & 10 & 0 & 1 & 0 & 0 & 1 \\
2 & $318-330$ & 8 & 0 & 0 & 1 & 0 & 0 \\
3 & Oficiais 330-348 & 33 & 5 & 8 & 6 & 1 & 2 \\
& Imitações 330-348 & 14 & 3 & 8 & 1 & 0 & 2 \\
4 & Oficiais 348-364 & 0 & 1 & 0 & 2 & 1 & 1 \\
& Imitações 354-358 & 0 & 11 & 118 & 4 & 2 & 6 \\
5 & $364-378$ & 0 & 0 & 0 & 17 & 12 & 6 \\
6 & $378-388$ & 0 & 0 & 0 & 0 & 9 & 6 \\
7 & $388-402$ & 0 & 0 & 0 & 0 & 16 & 96 \\
8 & Imitações do IV & 0 & 2 & 10 & 25 & 3 & 23 \\
Total & & 65 & 22 & 145 & 56 & 44 & 146 \\
\hline
\end{tabular}

Tabela 1: tabela de composição dos lotes de moedas estudados - Ile-de-France, séc IV. Fonte: Foucray (1997).

\section{Comunidades rurais e desenvolvimento econômico}

Como afirmado anteriormente, a partir dos dados acima apresentados foi elaborado um modelo para a Gália setentrional tardo-romana que propõe, ao contrário de empobrecimento das regiões rurais, crescimento econômico, afirmando até mesmo a possibilidade de melhoria dos padrões de vida das classes subalternas das zonas rurais (Van Ossel 2006). Esse modelo apresentaria as seguintes características: (1) intensificação da produção rural e urbana; (2) maior dinamismo dos processos de distribuição e circulação; (3) estímulo das relações econômicas locais por parte da administração imperial (via sistema fiscal e da presença militar);(4) criação de mercados locais e aprofundamento das conexões entre mercados locais, regionais e inter-regionais; e (5) ascensão social e melhoria do padrão de vida expressa na integração das classes subalternas a esses mercados locais e regionais.

Esbocei acima um exame preliminar dos limites e das potencialidades presentes na documentação arqueológica para sustentar esses modelos, e há uma característica deles que considero um avanço crucial: a visibilidade que eles têm dado às classes subalternas, inclusive em termos de sua agência histórica. Porém, o maior fator favorável talvez seja a insustentabilidade do modelo anterior de crise e empobrecimento catastróficos das regiões rurais.

Volto agora ao problema esboçado no título desse artigo: os pressupostos teóricos (e contexto ideológico) desse novo modelo de compreensão da paisagem rural do norte da Gália, assim como as conformações sociais, políticas e ideológicas que influenciam minha recepção dessa produção acadêmica.

No que diz respeito ao contexto histórico e ideológico dessa mudança de paradigmas na História e Arqueologia rurais, é importante ter em mente que as percepções de intensificação e crescimento econômico tardo-romano apareceram conforme se reformulava a perspectiva modernista no estudo da Economia Antiga ${ }^{4}$. Essa reformulação tem sido acompanhada nas últimas duas décadas pelo uso da New Institutional Economics (NIE) como enquadramento teórico. A grande contribuição da NIE foi estabelecer critérios teóricos que permitem o uso das teorias econômicas ortodoxas em sociedades sem economia capitalista. Estes critérios atenuam o anacronismo do seu emprego para

4 Uma rápida introdução ao debate está em Morley (2004: 31-47). 
sociedades pré-capitalistas porque traduzem para o esquema conceitual da economia as diferentes conformações sociais e culturais que influenciariam o comportamento econômico dessas sociedades.

Assim, para a NIE, embora o funcionamento da economia de uma sociedade seja entendido a priori como baseado em modelos postulantes de mercados em equilíbrio e atores pautados por racionalidade de maximização dos ganhos é organizado em torno de e constrangido por instituições culturalmente enraizadas que estabelecem "custos de transação", os quais, por sua vez, podem ser divididos entre custos derivados de busca por informação, de formas de negociação e de garantias legais e coercitivas para contratos (North 1990: 27-35). Ou seja, essa abordagem permite uma combinação da teoria econômica tradicional com elementos de história cultural (North 1990: 131-140), "substantivizando" de certa forma o formalismo da antiga abordagem modernista.

Muito embora, nem todos os estudiosos que contribuíram para a revalorização do cenário econômico da Antiguidade Tardia sejam simpáticos a esse enquadramento - muitos não são (Giardina 2007) -, ele tem se constituído sistematicamente na abordagem hegemônica na História Econômica da Antiguidade. Ousaria dizer que a consolidação dessa abordagem se dá em parte por, dentro desse contexto, ela responder melhor às questões colocadas pelo antigo modelo modernista e a alguns dos mais importantes desafios teóricos colocados pelo substantivismo de matriz finleyana. Assim, para muitos autores hoje, a NIE parece ser o ponto de partida para superação da tradicional dicotomia primitivismo-modernismo 5 . Contudo, não é possivel ignorar que seu sucesso também se deu em parte por causa do contexto social das últimas décadas de avanço da ideologia liberal e neoliberal na sociedade e de hegemonia da teoria econômica ortodoxa

5 O predomínio dessa perspectiva é muito bem representado pelas contribuições presentes na mais recente The Cambridge economic history of the Greco-Roman world (Scheidel, Morris \& Saller 2007). Cf. sua recepção crítica (Bang 2009) e sua celebração (Zuiderhoek 2015). nos cursos de economia; um contexto mais receptivo à projeção de teorias e modelos que usam valores e parâmetros da economia moderna como base de avaliação histórica das sociedades pré-capitalistas.

Embora esteja apontando o amplo e geral contexto histórico e ideológico que tornou a NIE e seu uso mais palatável para estudiosos da Economia Antiga, meu objetivo não é esboçar tais relações e acusar tais pesquisadores de anacronismo, mas refletir sobre tais contextos e, por causa disso, penso que o próprio lugar (histórico e ideológico) de onde meu trabalho é realizado também deva ser levado em consideração. Minha pesquisa vem sendo realizada num ambiente intelectual e político bem específico: o do neodesenvolvimentismo brasileiro da última década e meia. Assim, acredito ser propício questionar de que maneira esse amplo programa político-econômico, não só brasileiro, mas latino-americano, que resgatou o desenvolvimentismo do meio do século XX e o reformulou no XXI pode ter influenciado a minha própria recepção dessas representações da paisagem rural da Gália tardoantiga setentrional.

Tomo emprestada uma lista de características do que seria o programa neodesenvolvimentista ${ }^{6}$ brasileiro (Boito Jr. 2012), baseado na experiência recente dos governos petistas: (1) elevação da dotação orçamentária estatal para financiamento de grandes empresas nacionais, com taxas de juro subsidiadas; (2) política externa de apoio às grandes empresas nacionais ou instaladas no país para exportação de mercadorias e capitais; (3) política econômica anticíclica - medidas para manter a demanda agregada nos momentos de crise econômica; (4) aumento da infraestrutura administrativa e maior presença do Estado em regiões antes periféricas, estimulando crescimento econômico regional; (5) incremento

\footnotetext{
6 A definição do neodesenvolvimentismo é pouco consensual. Para descrições positivas e favoráveis ao uso do termo, cf. Bresser-Pereira (2015) e Lamoso (2012); para uma crítica que recusa que se possa chamar o programa político econômico brasileiro de 2003 ao presente de desenvolvimentista, cf. Gonçalves (2012). Tomo a perspectiva de Boito Jr. por ao mesmo tempo reconhecer a validade da terminologia e problematizar o processo.
} 
das rendas das classes subalternas e estímulo à sua participação no mercado interno, do qual eram previamente marginalizadas.

Dentre essas características do neodesenvolvimentismo, o item "5" é o que mais impacta o cotidiano das pessoas e, por sua vez, o que teria criado a experiência imediata de melhora no padrão de vida das classes trabalhadoras brasileiras. Sem nenhuma surpresa, esse é o elemento ao qual os defensores do programa mais acentuam em período eleitoral, o que sinaliza a força ideológica conformada por essa experiência. Chamo atenção para a semelhança desse item com os itens "4" e " 5 " da minha descrição do modelo para a Gália setentrional. Também é significativa a semelhança entre o item "3" da descrição da Gália e o item "4" do neodesenvolvimentismo?

Como pesquisador suscetível cotidianamente à ideologia gerada pela experiência de "melhora de padrão de vida", penso que o caminho para desnaturalizar essa semelhança é entender o contexto formativo (tácito) de nossos modelos e conceitos. Não basta, para isso, apenas acusar a influência ideológica do neoliberalismo, ou do neodesenvolvimentismo, na academia, pois isso aponta para um problema ainda mais fundamental. A ideia de uma economia culturalmente engastada produz modelos e conceitos que, quando utilizados para compreender sociedades pré-capitalistas ou não, funcionam muito bem com estruturas produtivas e de distribuição de pequena escala e em equilíbrio, nas quais noções de reciprocidade são operacionais. Contudo, mesmo quando partem de um enquadramento substantivista ou marxista, os estudiosos ou descartam os dados empíricos do crescimento econômico, minimizando seus impactos em suas representações dessas sociedades pré-capitalistas, ou só conseguem conceber crescimento e desenvolvimento econômico retomando a analogia com a lógica da acumulação capitalista. Isto é, mesmo os críticos da visão formalista e modernista do passado têm dificuldades em pensar o crescimento, o desenvolvimento econômico e o bem-estar social com categorias que não sejam pautadas pela lógica de troca de mercadorias e acumulação de capital. Não me restringindo apenas aos meus estudos sobre a Gália tardo-romana, mas a um problema mais amplo, pergunto-me: não seria possível conceber o desenvolvimento e crescimento de tais sociedades em outros termos conceituais?

SILVA, U.G. Gallo-roman rural archaeology and modern ideology. R. Museu Arq. Etn., 28: 42-57, 2017.

Abstract: This paper aims to evaluate recent historiographical representations of the late Roman countryside in Gaul. With the growth and expansion of the studies on rural archaeology in recent times, models postulating economic and commercial growth in the rural areas of the empire progressively replaced the previously held idea of a decadent Roman empire. Taking into account the special case of Late Roman north Gaul, this paper will focus on the discussion of some of the methods of investigation in which are based the results of this recent trend of Rural Archaeology: the role of survey archaeology in the discovery of sub-villa sites and the interpretation of these sites as local markets. Those models of economic growth have appeared in the context of a return to the modernist perspective in the study of Ancient Economy, based mainly in the use of New Institutional Economics as theoretical framing. Having that in mind, I render as

7 Muito embora as características "1" a "3" sejam potencialmente disparadoras do aguçado sentido "antianacronismo" do historiador "substantivista" do mundo antigo, há modelos de História Econômica da Antiguidade em circulação que não têm problema algum em usar esse tipo de conceituação, cf. Bowman \& Wilson (2013). 
problematic both that framing of the archaeological data and the application of capitalist criteria of growth and development for the Ancient World. Moreover, I try to draw from those new studies suggestions on how to approach the archaeological data to create more complex and dynamic models of social and economic process than those the twentieth-century historiography offered to the understanding of Late Roman Gaul.

Keywords: Roman Gaul; Peasantry; Rural Archaeology; Local markets; Regionalization.

\section{Referências bibliográficas}

Anderson, P. 2000. Passagens da antiguidade ao feudalismo. Brasiliense, São Paulo.

Arce, J. 1993. La Penisola Iberica. In: Schiavone, A. (Org.). Storia di Roma. vol. III: Letà tardoantica pt. II: I luoghi e le culture. Einaudi, Torino, 379-403.

Bagnall, R.S. 2005. Evidence and models for the economy of Roman Egypt. In: Morris, I.; Manning, J.G. The ancient economy: evidence and models. Stanford University Press, Stanford, 187-204.

Banaji, J. 2007. Agrarian change in late Antiquity. Gold, labour, and aristocratic dominance. Oxford University Press, Oxford.

Bang, P.F. 2009. The ancient economy and new institutional economic. Journal of Roman Studies 99: 194-206.

Bayard, D. 1998. La sigillé d’Argonne, un paramètre essentiel pour l'établissement de la chronologie du Ve siècle dans le Nord de la Gaule. In: Delestre, X.; Périn. P. (Orgs.). La datation des structures et des objets du haut moyen âge. Association française d’archéologie mérovingienne, St-Germain-enLaye, 7-20.

Becker, J.A.; Terrenato, N. 2012. Roman republican villas: architecture, context, and Ideology. University of Michigan Press, Ann Arbor.

Boito Jr, A. 2012. As bases políticas do neodesenvolvimentismo. In: Anais do 9 Fórum Econômico da FGV, 2012, São Paulo.
Bowden, W.; Lavan, L.; Machado, C. 2004. Recent research on the late antique countryside. Brill, Leiden.

Bowman, A.; Wilson, A. 2013. Introduction: quantifying Roman agriculture. In: Bowman, A.; Wilson, A. The Roman agricultural economy. Organization, investment and production. Oxford University Press, Oxford, 1-32.

Bresser-Pereira, L.C. 2015. Reflecting on new developmentalism and classical developmentalism. Textos para Discussão da Escola de Economia de São Paulo da Fundação Getulio Vargas 395. Disponível em: <https://goo.gl/4fkrEx>. Acesso em: 10/07/2015

Brown, P. 1971. The world of late antiquity: AD 150750. Routledge, London.

Cameron, A. 1993. The Mediterranean World in late antiquity: AD 395-700. Routledge, London.

Carrié, J.-M. 1982. Le "colonat du Bas-Empire”: un mythe historiographique? Opus 1(2): 351-371.

Carrié, J.-M. 1983. Un roman des origines: les généalogies du "colonat du Bas-Empire". Opus 2(1): 205-251.

Carrié, J.-M.; Rousselle, A. 1999. L'Empire romain mutation: des Sévères à Constantin, 192-337. Éditions du Seuil, Paris. 
Chavarría, A.; Lewit, T. 2004. Archaeological research on late antique countryside: a bibliographical essay. In: Bowden, W.; Lavan, L.; Machado, C. Recent research on the late antiquity countryside. Brill, Leiden, 3-51.

De Blois, L. 2002. The crisis of the third century A.D. in the Roman Empire: a modern myth? In: De Blois, L.; Rich, J. The transformation of economic life under the Roman Empire: proceedings of the second workshop of the International Network Impact of Empire (Roman Empire, C. 200 B.C. A.D. 476), Nottingham, July 4-7, 2001. J.C. Gieben, Amsterdam, 204-217.

Dossey, L. 2010. Peasant and empire in Christian North Africa. University of California Press, Berkeley.

Dyson, S.L. 2003. The Roman countryside. Duckworth, London.

Fentress, E. 1993. La Numidia. In: Schiavone, A. (Org.). Storia di Roma. vol. III: Letà tardoantica pt. II: I luoghi e le culture. Einaudi, Torino, 351-362.

Février, P.-A. 1993. Le Gallie meridionali. In: Schiavone, A. (Org.). Storia di Roma. vol. III: Letà tardoantica pt. II: I luoghi e le culture. Einaudi, Torino, 405-427.

Finley, M. I. 1999. The ancient economy. University of California Press, Berkeley.

Foucray, B. 1997. La circulation monétaire dans les campagnes de l'antiquitité tardive: l'exemple francilien. In: Ouzolias, P.; Van Ossel, P. Les campagnes de I'lle de france de Constantin à Clovis. Colloque de Paris. Raports et synthèses de la Deuxième Journée. Document de travail, III. CNRS, Paris, 42-49.

Ghedini, F. 1993. L'Africa Proconsulare. In: Schiavone A. (Org.). Storia di Roma. vol. III: Letà tardoantica pt. II: I luoghi e le culture. Einaudi, Torino, 309-325.

Giardina, A. 2007. Marxism and historiography: perspectives on Roman history. In: Wickham, C.
(Org.). Marxist history-writing for the twenty-first century. Oxford University Press, Oxford, 15-31.

Gonçalves, R. 2012. Governo Lula e o nacionaldesenvolvimentismo às avessas. Revista da Sociedade Brasileira de Economia Política 31: 5-30.

Grey, C. 2011. Constructing communities in the late Roman countryside. Cambridge University Press, Cambridge.

Heather, P. 2006. The fall of the Roman Empire. A new history of Rome and the barbarians. Oxford University Press, Oxford.

Horden, P.; Purcell, N. 2000. The corrupting sea: a study of Mediterranean history. Blackwell, Oxford.

Lamoso, L.P. 2012. "Neodesenvolvimentismo" brasileiro: implicações para a integração regional no âmbito do Mercosul." Sociedade \& Natureza 24(3): 391-404.

Leveau, P. 2007. The western provinces. In: Scheidel, W.; Morris, I.; Saller, R. (Orgs.). The Cambridge economic history of the Greco-Roman world. Cambridge University Press, Cambridge, 651-670.

Liebeschuetz, W. 2007. Was there a crisis of the third century? In: Hekster, O.; Kleijn, G.; Slootjes, D. Crises and the Roman Empire: proceedings of the seventh workshop of the International Network Impact of Empire, Nijmegen, June 20-24, 2006. Brill, Leiden, 11-20.

Louis, E. 2004. A de-romanized landscape in Northern Gaul: the Scarpe Valley form the 4th to the 9th century AD. In: Bowden, W.; Lavan, L.; Machado, C. (Orgs.). Recent research on the late antique countryside. Brill, Leiden, 479-504.

Mac Gaw, C.G. 2012. Capitalismo romano, modernismo e marxismo. A propósito de algumas ideias sobre o trabalho assalariado. História \& Luta de Classes 8(14): 23-27.

Matthews, J.F. 1990. Western aristocracies and imperial court. AD 364-425. Oxford University Press, Oxford. 
Mattingly, D.J.; Hitchner, R.B. 1995. Roman Africa: an archaeological review. The Journal of Roman Studies 85:165-213.

Morley, N. 2004. Theories, models, and concepts in ancient history. Routledge, London.

North, D.C. 1990. Institutions, institutional change and economic performance. Cambridge University Press, Cambridge, 1990.

Ouzolias, P.; Van Ossel, P. 1997. Les campagnes de I'lle de france de Constantin à Clovis. Colloque de Paris. Raports et synthèses de la Deuxième Journée. Document de travail, III. CNRS, Paris.

Ouzolias, P.; Van Ossel, P. 2000. Rural settlement economy in Northern Gaul in the Late Empire: an overview and assessment. Journal of Roman Archaeology 13: 133-160.

Redknap, M. 1988. Medieval pottery production at Mayen. In: Gaimster, D.R.M.; Redknap, M.; Wegner, H.-H. (Eds.). Zur Keramik des Mittelalters und der beginnenden Neuzeit im Rheinland. BAR Internacional Series 440, Oxford, 3-37.

Saller, R. 2005. Framing the debate over growth in the ancient economy. In: Morris, I.; Manning, J.G. The ancient economy: evidence and models. Stanford University Press, Stanford, 223-238.

Scheidel, W.; Morris, I.; Saller, R. (Orgs.). 2007. The Cambridge economic history of the Greco-Roman world. Cambridge University Press, Cambridge.

Schiavone, A. 2005. Uma história rompida: Roma antiga e Ocidente moderno. Edusp, São Paulo.

Staerman, E.M. 1980. La caída del regimen esclavista. In: Bloch, M. et al. La transición del esclavismo al feudalismo. Akal, Madrid, 59-107.

Tuffi, S.R. 1993. Le Gallie setentrionali. In: Schiavone, A. (Org.). Storia di Roma. vol. III: Letà tardoantica pt. II: I luoghi e le culture. Einaudi, Torino, 429-441.

Van Ossel, P. 2006. Rural impoverishment in Northern Gaul at the end of antiquity: The contribution of archaeology. In: Bowden, W.; Lavan, L.; Machado, C. (Orgs.). Social and political life in late antiquity. Brill, Leiden, 534-565.

Vera, D. 1986. Forme e funzioni della rendita fondiaria nella tarda Antiquità. In: Giardina, A. (Org.). Societá romana e Impero TardoAntico. Vol. I: Instituzioni, ceti, economie. Laterza, Bari, 367-447.

Weber, M. 1983. As causas sociais da decadência da cultura antiga. In Cohn, G. (Org.) Weber. Ática, São Paulo, 37-57.

Ward-Perkins, B. 2000. Land, Laborand Settlement. In: Cameron, A.; Ward-Perkins, B.; Whitby, M. (Orgs.), The Cambridge ancient history. Vol. XIV: late antiquity: empire and successors A.D. 425600. Cambridge University Press, Cambridge, 315-345.

Ward-Perkins, B. 2005. The fall of Rome: and the end of civilization. Oxford University Press, Oxford.

Wickham, C. 2005. Framing the early middle ages. Europe and the Mediterranean, 400-800. Oxford University Press, Oxford.

Wightman, E.M. 1978. Peasants and potentates: an investigation of social structure and land tenure in Roman Gaul. American Journal of Ancient History 3(2): 97-128.

Zuiderhoek, A. 2015. Introduction: land and natural resources in the Roman World in historiographical and theoretical perspective. In: Erdkamp, P.; Verboven, K.; Zuiderhoek, A. Ownership and exploitation of land and natural resources in the Roman world. Oxford University Press, Oxford, 1-48. 